\title{
Adolescents at ultra-high risk for psychosis with and without 22q11 deletion syndrome: A comparison of prodromal psychotic symptoms and general functioning
}

\author{
Marco Armando a,b,c,*, Paolo Girardi b , Stefano Vicari a , Deny Menghini a , Maria Cristina Digilio ${ }^{\text {d }}$, \\ Maria Pontillo ${ }^{a}$, Riccardo Saba ${ }^{\mathrm{e}}$, Luigi Mazzone ${ }^{\mathrm{a}}$, Ashleigh Lin ${ }^{\mathrm{c}}$, Claudia M. Klier ${ }^{\mathrm{f}}$, \\ Miriam R. Schäfer ${ }^{\mathrm{f}, \mathrm{g}}$, G. Paul Amminger ${ }^{\mathrm{f}, \mathrm{g}}$ \\ a Child and Adolescence Neuropsychiatry Unit, Department of Neuroscience, Children Hospital Bambino Gesù, Piazza Sant'Onofrio 4, 00100, Rome Italy \\ b School of "Early Intervention in Psychosis", Sant' Andrea Hospital and "Sapienza" University of Rome NESMOS Department, via di Grottarossa 1035,00185, Rome Italy \\ c School of Psychology, University of Birmingham, Edgbaston, Birmingham, B15 2TT, UK \\ d Medical Genetic Unit, Pediatric Department, Children Hospital Bambino Gesù, Piazza Sant'Onofrio 4, 00100, Rome, Italy \\ e Department of Neurology and Psychiatry, "Sapienza" University of Rome, Viale dell'Università 30, 00185, Rome, Italy \\ ${ }^{\mathrm{f}}$ Department of Child and Adolescent Psychiatry, Medical University of Vienna, Währinger Gürtel 18-20, A-1090 Vienna, Austria \\ g Orygen Youth Health Research Centre, Centre for Youth Mental Health, University of Melbourne, 35 Poplar Rd (Locked Bag 10), Parkville 3052, Victoria, Australia
}

\section{A R T I C L E I N F O}

\section{Article history:}

Received 14 January 2012

Received in revised form 1 April 2012

Accepted 30 April 2012

Available online 23 May 2012

\section{Keywords:}

22q11.2 deletion syndrome

Ultra-high risk

Schizophrenia

Early intervention

Prodrome

\begin{abstract}
A B S T R A C T
Objective: Genetic syndromes related to psychosis have become increasingly important for exploring the trajectory that leads to psychosis onset. A very significant opportunity for mapping earlier phases of the trajectory can be found in 22q11.2 deletion syndrome (22q11DS). Comparative studies have shown that schizophrenic disorder in 22q11DS largely resembles schizophrenia in the general population, but only few studies have investigated the features of prodromal symptoms in 22q11DS. The aim of the present study was to investigate differences and similarities between two samples: patients with 22q11DS clinically at risk for psychotic onset (UHR + 22q11DS group) and patients at clinical high risk for psychotic onset (UHR group).

Method: The study was conducted on a sample of 30 individuals UHR + 22q11DS and 81 individuals at UHR without 22q11DS. The two groups were compared on positive, negative and depressive symptoms, level of general functioning and IQ.

Results: There was a significant group difference in negative symptoms, but no significant differences were found for positive, global and total symptoms. The UHR + 22q11DS group showed a lower level of general functioning. The clinical profile of the UHR $+22 q 11 D S$ group was clearly more homogeneous.

Conclusions: Even if the two UHR groups are comparable in terms of positive symptoms, the UHR +22q11DS have a specific clinical pattern characterized by higher negative symptoms, lower general functioning and an older age of onset of the UHR state. This finding may be of clinical value for the development of specific therapeutic intervention for UHR +22q11DS, and of theoretical value since the two groups may share only some underlying etiopathogenetic mechanisms.
\end{abstract}

(c) 2012 Elsevier B.V. All rights reserved.

\section{Introduction}

The identification of individuals at high risk for severe psychiatric disorders, particularly schizophrenia, has become one of the premiere research topics in psychiatry over the past decade. This has been driven by the view that the early identification of disorder may improve outcome (Yung et al., 1996; Birchwood et al., 1997) and shed light on the etiopathogenic processes involved (Birchwood et al., 1998; Parnas, 2000; Klosterkötter et al., 2001; Yung et al., 2004; Schultze-Lutter, 2009). The most commonly used method to identify help-seeking

\footnotetext{
* Corresponding author at: Department of Neuroscience, Children Hospital Bambino Gesù, Piazza Sant'Onofrio 4, I-00165, Roma, Italy. Tel.: + 3906 68592734; fax: + 3906 68592450.

E-mail address: marco.armando@opbg.net (M. Armando).
}

individuals in the putatively prodromal phase of psychotic disorders, specifically schizophrenia, has been the "ultra-high risk" (UHR) approach (Yung et al., 1996). These criteria combine known trait and state risk factors for the onset of schizophrenia, including attenuated positive psychotic symptoms, brief self-limiting psychotic symptoms, trait vulnerability and functional decline (Yung et al., 2003; Yung et al., 2004).

Genetic syndromes related to schizophrenia have become increasingly important for exploring the trajectory of psychosis onset. Among these, a very significant opportunity for mapping earlier phases of this trajectory exists in 22q11.2 deletion syndrome (22q11DS) (Insel, 2010; Karayiorgou et al., 2010), a syndrome associated with a microdeletion of chromosome 22 band q11 with an estimated prevalence of between 1:2500 and 1:4000 live births (Scambler et al., 1992). 22q11DS is a complex disorder with multiple abnormalities affecting a large number of tissues and organs, many of which are derived from neural crest cells 
(Robin and Shprintzen, 2005; Shprintzen, 2005). The diagnosis is defined by the deletion of DNA from chromosome 22 at the q11.2 band spanning the region that is regarded as critical for multiple functions. The physical and neurobehavioural phenotype of the syndrome includes high rates of congenital dysmorphic features (Scutt et al., 2001), developmental structural brain abnormalities (Chow et al., 1999), and a typical cognitive phenotype (Swillen et al., 2000) characterized by general cognitive functioning in the low borderline range, while verbal memory, reading decoding and spelling skills are areas of relative strength (Antshel et al., 2008).

This syndrome is also characterized by high rates of psychiatric disorders (Gothelf et al., 2007 particularly schizophrenia (Bassett and Chow, 1999; Murphy, 2005). Studies of school-age children have shown that individuals with 22q11DS have high rates of psychiatric and behaviours disorders, such as attention-deficit/hyperactivity disorder, generalised anxiety disorder and obsessive-compulsive disorder (Feinstein et al., 2002; Gothelf et al., 2004; Antshel et al., 2006). However, their incidence in 22q11DS is no higher than in other developmental disorders (Feinstein et al., 2002; Antshel et al., 2006), suggesting that that they are not indicative of a behavioural phenotype specifically associated with this syndrome (Feinstein et al., 2002).

By contrast, schizophrenia is specifically associated with 22q11DS (Karayiorgou et al., 1995; Xu et al., 2008). Half of the adolescents with 22q11DS report transient psychotic experiences, while up to onethird of affected adults are diagnosed with schizophrenia (Murphy et al., 1999; Bassett et al., 2003; Green et al., 2009). This rate of transition is comparable to the rates observed in UHR risk groups (Yung et al., 2004; Ruhrmann et al., 2010), making 22q11DS one of the highest known risk factors for schizophrenia. Moreover, 22q11DS is found in up to one in 50 patients with schizophrenia, with reports ranging from $0.3 \%$ to $2 \%$ (Karayiorgou et al., 1995; Arinami, 2006; Stefansson et al., 2008). The occurrence of 22q11DS is even higher in patients with childhood-onset schizophrenia (5.7\%) (Sporn et al., 2004). For this reason, 22q11DS could represent an ideal human model to explore issues related to early diagnosis and intervention for schizophrenia-related abnormalities. Identifying shared and unique features for 22q11DS and schizophrenia is critical for the understanding of genetic and neural mechanisms underlying both disorders.

Comparative studies have shown that schizophrenic illness associated with 22q11DS largely resembles the illness as it presents in the general population (Karayiorgou et al., 2010). For example, Murphy et al. (1999) found that patients with schizophrenia and 22q11DS had similar positive symptoms, less pronounced negative symptoms and an older age of onset than a demographically-matched group of schizophrenia patients without 22q11DS. Other comparisons showed no significant differences in age of onset, life or cross-sectional positive or negative symptoms, or global functioning between adults with schizophrenia with and without 22q11DS (Bassett et al., 1999; 2003).

Few studies have investigated the early signs and symptoms of schizophrenia in patients with 22q11DS. Retrospective studies have found that the incidence of major depressive disorder, attentiondeficit/hyperactivity disorder, phobias, enuresis and impaired social adaptive skills is higher in adolescents with 22q11DS who developed schizophrenia than in healthy controls (Gothelf et al., 2007; Feinstein et al., 2002; Antshel et al., 2006; Debbané et al., 2006; Antshel et al., 2010). Only two studies have prospectively explored specific prodromal symptoms that are predictive of schizophrenia onset in 22q11DS. In the first (Gothelf et al., 2007), 32\% of the sample developed schizophrenic disorder during follow-up. The development of psychotic symptoms between the ages of 12 and 18 years was best predicted by the presence of attenuated psychotic symptoms, anxiety and depression at age 12. In a second study (Antshel et al., 2010), a total of 70 children with 22q11DS, 27 of their unaffected siblings and 25 community controls were followed from childhood into mid-adolescence. With very low false positive rates, the best predictor of adolescent prodromal psychotic symptoms was parent ratings of childhood odd/eccentric symptoms and child performance on a test of an executive functioning.

Even fewer studies have investigated the features of prodromal symptoms in patients with 22q11DS. In such studies, individuals with 22q11DS showed higher positive, negative (Rockers et al., 2009; Antshel et al., 2010; Stoddard et al., 2010), disorganized (Antshel et al., 2010; Stoddard et al., 2010), and general (Stoddard et al., 2010) symptoms compared to general population. A recent study compared demographically-matched groups of 23 individuals with Schizotypal Personality Disorder (SPD), 23 with 22q11DS, and 23 controls on the Structured Interview for Prodromal Syndromes (SIPS) (Shapiro et al., 2011). Both risk groups showed elevated prodromal symptoms, with approximately $60 \%$ of individuals with 22q11DS and 70\% with SPD meeting symptom criteria for a prodromal psychosis syndrome. No study has specifically explored the features of prodromal symptoms in a subsample of 22q11DS clinically-defined as UHR for psychosis, and none have compared this group to UHR samples without (known) 22q11DS.

The aim of the present study was to investigate differences and similarities between two samples: patients with 22q11DS and UHR (UHR + 22q11DS; $n=30$ ), and patients at UHR (UHR group; $n=81$ ). We tested the hypotheses that (i) the two groups would be comparable in severity of positive symptoms, the core symptoms for a diagnosis of a psychotic disorder; (ii) the UHR + 22q11DS group will have higher severity of negative symptoms and general impairment. These hypotheses were based on literature showing that negative symptoms are related to neuroanatomical and functioning abnormalities of the ventrolateral prefrontal cortex and ventral striatum (Suzuki et al., 2005; Amodio and Frith, 2006; Goghari et al., 2010) which are frequently reported in patients with 22q11DS (Gothelf et al., 2005; Gothelf et al., 2007; Schaer et al., 2009). Additionally, lower general functioning can be, at least partially explained, by the close relationship between functioning and negative symptoms evidenced in a UHR group (Lin et al., 2011).

\section{Methods}

\subsection{Participants}

The study was conducted on a sample of 30 individuals with 22q11DS at UHR of psychosis (UHR + 22q11DS) and 81 individuals at UHR of psychosis without 22q11DS (UHR).

UHR + 22q11DS patients were recruited from the Child and Adolescent Neuropsychiatry Unit and the Clinical Genetic Unit of the Clinical and Research Hospital Bambino Gesù of Roma between 2009 and 2011. They were identified by standard cytogenetic studies using fluorescence in situ hybridisation (FISH) and a probe from the commonly deleted 22q11.2 region. After diagnoses, individuals underwent a venous blood sample for genotypic analysis. UHR patients without 22q11DS were consecutive admissions to a specialised psychosis detection and treatment unit at the Department of Child and Adolescent Psychiatry, Medical University of Vienna, Austria, between 2004 and 2006. This group was recruited for a randomized controlled trial of omega-3 fatty acids vs placebo which is described elsewhere (Amminger et al., 2010). FISH analyses could not be performed on UHR group because the recruitment was developed for another study (Omega-3 RCT) and therefore not approved by the local Ethic Committee. However, as recently argued by Shapiro et al. (2011), individuals with 22q11.2 deletions are unlikely to be found in standard UHR samples. As previously mentioned, low base rates of the $22 \mathrm{q} 11.2$ deletion in the general population (1:2500-1:4000), as well as in schizophrenia (0.3\%-2\%) (Karayiorgou et al., 1995; Arinami, 2006; Stefansson et al., 2008), make it very unlikely that any individual in the UHR group would have the deletion. Both UHR groups were free of antipsychotic medication. 
UHR status was defined by the presence of at least one of the following well-validated criteria: attenuated positive psychotic symptoms (Group 1); brief limited intermittent psychotic symptoms (BLIPS; Group 2); and genetic risk plus a deterioration in functioning (Group 3). The presence of attenuated psychotic symptoms and BLIPS were determined by semi-structured interview applying the Positive and Negative Syndrome Scale (PANSS) (Kay et al., 1987) cut-off scores for symptom severity proposed by Morrison et al. (2004), and frequency and duration criteria of Yung et al. (1998). Detailed UHR criteria are listed in Table 1. Exclusion criteria were organic mental disorder, prior diagnosis of psychotic disorder, mental retardation or the presence of any documented neurological condition.

\subsection{Procedure}

The study was approved by the Ethics Committee of the Medical University of Vienna and the Ethics Committee of the Clinical and Research Hospital Bambino Gesù of Roma and was conducted in agreement with the Italian Association of 22q11.2 microdeletion syndrome (AIdel 22) within a wider project aimed at the prevention of psychopathological disorders in patients with 22q11DS. All participants provided written informed consent and parental consent for those under 18 years of age.

\subsection{Measures}

The PANSS (Kay et al., 1987) was used to assess psychiatric symptoms. At both sites, raters were experienced clinicians trained in the administration of the PANSS using a standard training video. Interrater reliability estimates for PANSS subscales were excellent at both sites (all intra-class correlation coefficients $>0.90$ ). The SCID-P for DSM-IV (First et al., 2002) and the K-SADS-PL (Kaufman et al., 1997) were used to ascertain psychiatric diagnoses. Functioning was measured with either the Global Assessment of Functioning (GAF) (APA, 1994) or Childhood Global Assessment Scale (CGAS). Depressive symptoms were assessed using the Montgomery Asberg Depression Rating Scale (MADRS) (Davidson et al., 1986). The Number-Combination Test (Oswald and Roth, 1987) and the Leiter-R (Roid and Miller, 1997) were used to assess current IQ.

\subsection{Statistical analysis}

Data were analysed using statistical software PASW 18. Since sample sizes were unequal, homogeneity of variance was confirmed using Levene's test. The assumption that psychopathological (PANSS scores; MADRS score; GAF or CGAS score) variables and IQ were normally

\section{Table 1}

Ultra-high risk criteria.

\footnotetext{
Group 1: Attenuated psychotic symptoms

Presence of symptom scores of 3 on the PANSS delusions scale, 2-3 on the PANSS hallucinations scale, 3-4 on PANSS suspiciousness or 3-4 on PANSS conceptual disorganization scale (frequency of symptoms $\geq 2$ times per week for a period of at least a week and not longer than 5 years, and to have occurred within the last year).

Group 2: Transient psychosis

Presence of symptoms scores of $\geq 4$ on PANSS hallucinations scale, $\geq 4$ on PANSS delusions scale, or $\geq 5$ on PANSS conceptual disorganization scale (symptoms not sustained beyond a week and resolve without antipsychotic medication, and have occurred within the last year).

Group 3: Trait plus state risk factors

Having a schizotypal personality disorder (as defined by DSM-IV) or a firstdegree relative with a DSM-IV psychotic disorder and a significant decrease in functioning from pre-morbid level, resulting in a decrease of $30 \%$ on the Global Assessment of Functioning Scale, maintained for at least a month and not longer than 5 years. The decrease in functioning needed to have occurred within the past year.

PANSS $=$ Positive and Negative Syndromes of Schizophrenia Scale.
}

distributed in the population was confirmed using the KolmogorovSmirnov test $(p>0.05)$. Therefore, groups were compared on demographic and clinical variables using chi-square analysis for categorical data. For continuous data, separated ANOVA and ANCOVA models were used covarying for IQ and MADRS scores. To control for multiple comparisons, Bonferroni correction was applied (0.05/6 psychopathological measures; critical $p$-value of 0.0083 ). Individual z-scores were considered as a measure of dispersion.

\section{Results}

\subsection{Demographic characteristics}

As shown in Table 2, the groups differed significantly on level of education, with a lower proportion of higher education in the UHR + 22qDS group $(p<0.001)$. The UHR $+22 q D S$ group also had lower current IQ $(p=0.001)$. There was no significant group difference in age.

\subsection{Comparisons between groups}

Table 2 summarized results on comparisons between individuals in the UHR and in UHR + 22qDS groups. The age of onset of the UHR condition was significantly lower in the UHR group (14.8 years vs 16.4 years), but duration of general psychiatric and attenuated psychotic symptoms before the assessment did not differ between groups.

There was a significant group difference in the PANSS negative subscale $(p=0.0081)$, with higher scores in the UHR $+22 q D S$ group. However, group differences in depressive symptoms were not significant $(p=0.08)$. Since differences in PANSS negative subscale could be influenced by IQ levels and depressive symptoms, IQ and MADRS scores were introduced as covariate variables in two separated ANCOVA analyses. Also after controlling for the influence of IQ and MADRS scores, results documented difference between groups in PANSS negative subscale (respectively, $F(1,108)=6.1, p=0.015 ; F(1,108)=4.59, p=0.034$ ).

Table 2

Demographic characteristics and psychiatric symptoms ultra-high risk and ultra-high risk + 22qDS groups.

\begin{tabular}{|c|c|c|c|}
\hline Variable & $\mathrm{UHR}+22 \mathrm{q} 11 \mathrm{DS}(n=30)$ & $\operatorname{UHR}(n=81)$ & Analyses \\
\hline Male, $N(\%)$ & $14(46.7 \%)$ & $27(33.3 \%)$ & $\chi^{2}=1.67 ; p=0.142$ \\
\hline \multicolumn{4}{|c|}{ Education, $N(\%)$} \\
\hline -Basic & $26(86.7 \%)$ & $37(46.8 \%)$ & $\chi^{2}=14.04 ; p<0.001$ \\
\hline -Higher & $4(13.3 \%)$ & $42(53.2 \%)$ & \\
\hline Age, $M(\mathrm{SD})$ & $16.7(1.5)$ & $16.5(1.8)$ & $F=1.74 ; p=0.193$ \\
\hline $\begin{array}{l}\text { Current IQ } \\
M(\mathrm{SD})\end{array}$ & $89.8(8.9)$ & $99.3(15.6)$ & $F=10.64 ; p=0.001$ \\
\hline $\begin{array}{l}\text { PANSS Positive, } \\
M(\mathrm{SD})\end{array}$ & $14.3(2.6)$ & $14.6(3.2)$ & $F=0.13 ; p=0.721$ \\
\hline $\begin{array}{l}\text { PANSS Negative, } \\
\quad M(\mathrm{SD})\end{array}$ & $16.8(3.2)$ & $13.8(5.8)$ & $F=7.28 ; p=0.0081$ \\
\hline $\begin{array}{l}\text { PANSS Global, } \\
M(\mathrm{SD})\end{array}$ & $32.4(4.9)$ & $30.1(6.9)$ & $F=2.61 ; p=0.109$ \\
\hline $\begin{array}{l}\text { PANSS Total, } \\
\quad M(\mathrm{SD})\end{array}$ & $63.6(9.3)$ & $58.5(13.4)$ & $F=3.56 ; p=0.06$ \\
\hline $\begin{array}{l}\text { GAF/CGAS, } \\
M(\mathrm{SD})\end{array}$ & $45.2(2.9)$ & $60.5(12.5)$ & $F=47.8 ; p<0.001$ \\
\hline $\begin{array}{l}\text { MADRS, } \\
M(\mathrm{SD})\end{array}$ & $21.3(6.1)$ & $18.2(8.7)$ & $F=3.15 ; p=0.08$ \\
\hline $\begin{array}{l}\text { Dsym } \\
\quad \text { (in months), } \\
M(\mathrm{SD})\end{array}$ & $22.2(12.1)$ & $19.4(14.1)$ & $F=0.91 ; p=0.34$ \\
\hline $\begin{array}{l}\text { Dpsym } \\
\quad \text { (in months), } \\
M(\mathrm{SD})\end{array}$ & $10.2(8.3)$ & $12.8(10.8)$ & $F=1.47 ; p=0.23$ \\
\hline $\mathrm{AOO}, M(\mathrm{SD})$ & $16.4(1.2)$ & $14.8(2.5)$ & $F=11.14 ; p=0.001$ \\
\hline
\end{tabular}

Notes. Dsym: duration of any psychiatric symptom before first assessment. Dpsym: duration of any psychotic symptoms before first assessment. AOO: age of onset of UHR condition. 
The UHR + 22qDS group showed a significantly lower level of general functioning (GAF or CGAS score) compared with the UHR group $(p<0.001)$. Also after controlling for the influence of IQ and MADRS scores, results showed difference between groups in level of general functioning (respectively $F(1,108)=42.13, p<0.00001 ; F(1,108)=$ 49.03, $p<0.00001)$.

However, no significant group differences were found for the PANSS positive $(p=0.72)$, total $(p=0.06)$ and global $(p=0.109)$ subscale scores. These results were confirmed also after controlling for IQ and for MADRS (after controlling for IQ PANSS positive $F(1,108)=0.11$, $p=0.74$, PANSS total $F(1,108)=3.37, p=0.07$ and PANSS global $F(1,108)=2.9, \quad p=0.09)$; after controlling for MADRS, PANSS positive $F(1,108)=1.22, p=0.27$, PANSS total $F(1,108)=1.02$, $p=0.31$ and PANSS global $F(1,108)=0.33, p=0.56$ ).

\subsection{Measures of variability}

Fig. 1 shows, for different measures, the distribution of the scores obtained by each participant in both groups. As a measure of dispersion, we transformed the score of each participants in z-score by considering the mean score (and the standard deviation) of the two groups on each measure.

\section{PANSS POSITIVE}

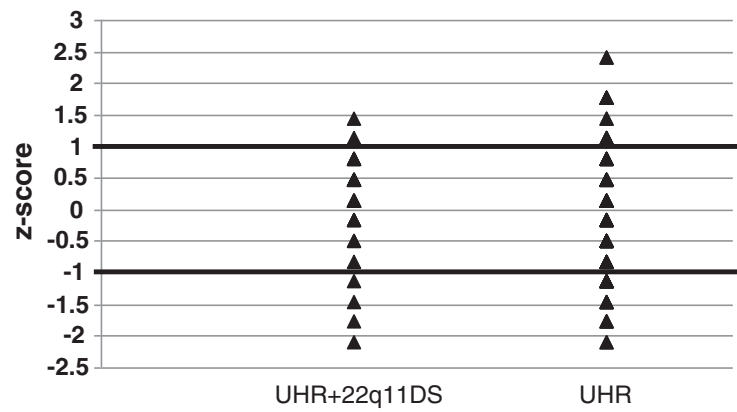

PANSS TOTAL

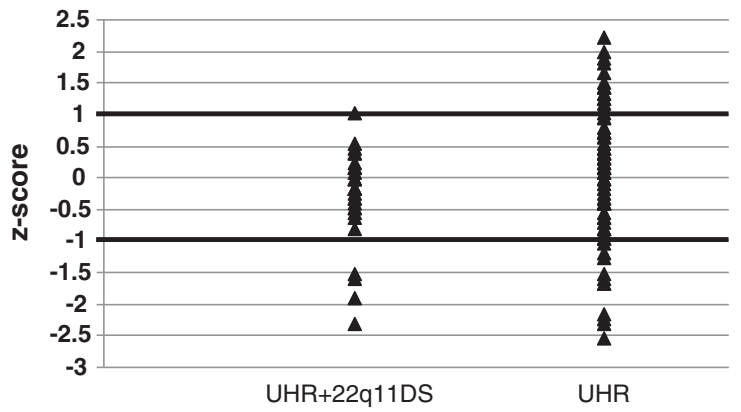

IQ

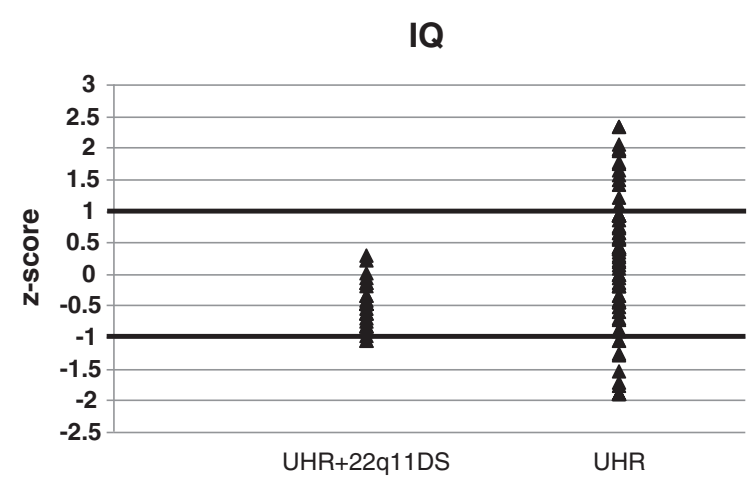

The proportion of UHR $+22 \mathrm{qDS}$ participants who had a score below or above the mean ( $<1$ or $>1 \mathrm{SD}$ ) on the PANSS positive and negative subscales and total score was $37 \%$. On the other hand, the proportion of the UHR group falling more than 1 SD from the mean was $20 \%$ for the PANSS positive and negative subscales, and $16.6 \%$ for the total PANSS score. Concerning the level of general functioning, the proportion of participants in the UHR $+22 q D S$ group who had a score more than $1 \mathrm{SD}$ from the mean was 33.3\% compared to $23.3 \%$ of the UHR group. Finally, 33.3\% of participants in the UHR +22qDS group had an IQ score more than 1 SD below or above the mean, while just 6.6\% of the UHR group showed IQ outside this range.

\section{Discussion}

To our knowledge, the current study is the first to compare a group of individuals with 22q11DS who were clinically at UHR for psychosis with another clinically-defined UHR group without 22q11DS. Although positive symptom levels were similar, UHR + 22q11DS showed higher negative symptoms, lower general functioning and an older age of onset of the UHR state. Investigating phenotypic similarities and differences between these UHR groups before the onset of frank psychosis is an important first step in the identification of shared and unique features

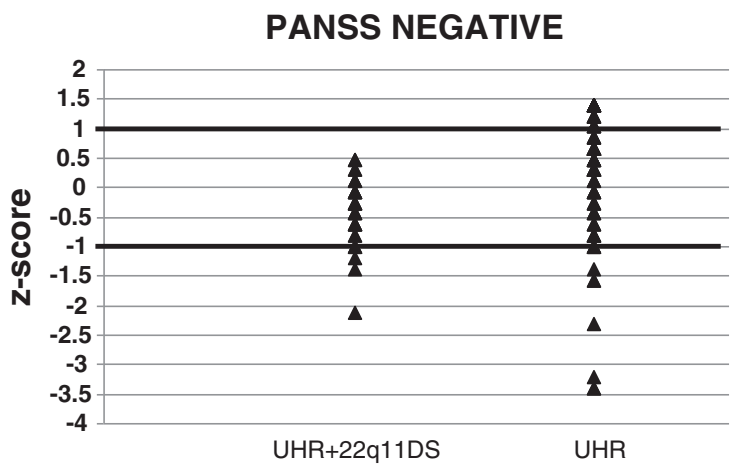

\section{GENERAL FUNCTIONING}

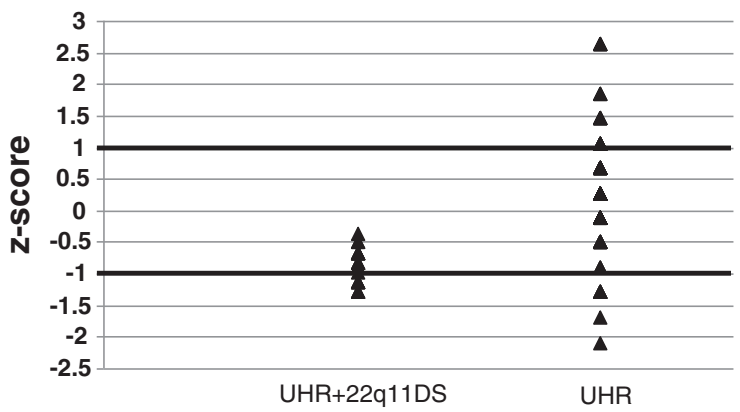

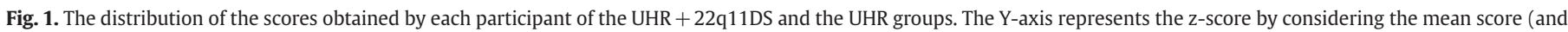
standard deviation) of the two groups on each measure. One standard deviation limit ( $\pm 1 \mathrm{SD})$ is marked on the Y-axis. 
underlying 22q11DS and schizophrenia. This is critical for beginning to understand the genetic and neural mechanisms underlying both conditions.

Our first hypothesis that the two groups would be comparable in terms of the severity of positive symptoms was confirmed. This is unsurprising given that the detection of UHR status is based on the presence and severity of attenuated positive psychotic symptoms. The second hypothesis was that the UHR + 22q11DS group would display greater severity of negative symptoms and general impairment. This was also confirmed. The UHR + 22q11DS group showed a mean negative symptom score three points higher than the UHR group, and a mean GAF/CGAS score 15 points lower. The greater severity of negative symptoms is consistent with the finding that negative symptoms are related to neuroanatomical and functioning abnormalities of the ventrolateral prefrontal cortex and ventral striatum (Suzuki et al., 2005; Amodio and Frith, 2006; Goghari et al., 2010) which are frequently reported in patients with 22q11DS (Gothelf et al., 2005; 2007; Schaer et al., 2009). Lower general functioning can be, at least partially explained, by the close relationship between functioning and negative symptoms evidenced in a UHR group (Lin et al., 2011) and schizophrenia samples (Herbener et al., 2005; Milev et al., 2005). Since severity of negative symptoms and general impairment are associated with a worse functional outcome following UHR (Lin et al., 2011), and a poorer long-term prognosis in schizophrenia (Tek et al., 2001; Chemerinski et al., 2006), specific treatment approaches (Murphy et al., 2006) should be developed for UHR + 22q11DS patients. For example, recent findings suggest the efficacy of Omega-3 fatty acids in reducing negative symptoms and functional impairment in UHR groups (Amminger et al., 2010; Amminger and McGorry, 2012).

Interestingly, the psychopathological profile of the UHR +22q11DS group was clearly more homogeneous than the UHR group. There are two likely reasons for this. This finding may be related to the predominant genetic aetiology of UHR symptoms in 22q11DS group compared to the multi-factorial, and greater environmental-related aetiology in the UHR group. This hypothesis is an extension of the "syndromespecific" hypothesis, derived from recent studies documenting that psychopathological risk in genetic syndromes might be specifically due to different neurobiological factors and to the abnormal brain development which may vary depending on the aetiology of genetic syndrome (Mervis and Robinson, 2000; Vicari et al., 2007). Secondly, many of the UHR subjects are likely to be false positives; only a minority will go on to develop frank psychotic illness (Fusar-Poli et al., 2012). Given this, their symptomatic profile would be expected to be more varied than the UHR + 22q11DS group.

This is the first study to compare a sample with 22q11DS thought to be in the putative prodromal period of psychotic illness with a clinical UHR group without 22q11DS. The strength of this sample is the relatively large cohort $(n=30)$ of patients with UHR +22q11DS. A further strength is that all participants were neuroleptic-naive, a rare occurrence in UHR research today. Findings should be interpreted in light of the fact that the two groups were assessed at different sites, which is an important limitation of this study. Although such practice is common, we cannot exclude the possibility that group differences may be accounted for by rater differences at the respective sites. However, this is unlikely given that $\mathrm{i}$ ) there were only significant group differences on some measures, suggesting it is not a spurious finding, ii) the same standardized training video was used in both sites. It is also possible that findings are related to the presence of, and living with, a chronic illness, rather than specific to 22q11DS and the psychosis prodrome. While unlikely, this cannot be ruled out without a "chronic illness control group".

In conclusion, these two UHR groups are comparable in terms of severity of positive symptoms, which are the core symptoms for a diagnosis of psychotic disorder. Most importantly however, the groups differ on the level of negative symptoms and functioning. This has implications from a therapeutic and prognostic perspective. Given that greater negative symptoms and lower quality of life at identification as UHR are associated with poor functional outcome many years later (Lin et al., 2011), specific early intervention strategies should be implemented for young people with UHR +22q11DS. These could be psychosocial and vocational interventions that target negative symptoms and factors associated with them, such as neurocognition (Lin et al., 2011). The use of omega-3 fatty acids as an intervention also merits further investigation since these have shown efficacy in reducing negative symptoms (Amminger et al., 2010; Amminger and McGorry, 2012). From a theoretical point of view, the findings of this study contribute to our understanding of the aetiology of schizophrenia. The 22q11DS group may represent a neurodevelopmental pathway to psychotic illness (Myin-Germeys \& van Os, 2007). This would differ from an affective pathway, which may be a more likely illness trajectory for individuals in the UHR group without 22q11DS that go on to develop psychosis. This is speculative and longitudinal studies designed specifically to compare the clinical, neuropsychological, genetic and neuroimaging profiles of clinical UHR groups with those of UHR + 22q11DS populations are necessary. These will hopefully improve knowledge of the etiopathogenetic mechanisms involved in schizophrenia, and the detection of early signs and symptoms that are highly predictive of future psychotic onset and prognosis.

\section{Role of Funding Source} None.

\section{Contributors}

- Marco Armando developed the study design, contributed in the assessment, in writing the paper and in the statistical analysis.

- Paolo Girardi contributed to the study design and in writing the paper.

- Stefano Vicari contributed in writing the paper.

- Deny Menghini contributed in writing the paper and in the statistical analysis.

- Maria Cristina Digilio contributed to the recruitment and assessment of the 22q11DS sample.

- Maria Pontillo contributed to the review of previous literature and in the assessment.

- Riccardo Saba contributed to the review of previous literature and in writing the paper.

- Luigi Mazzone contributed significantly in improving the paper following the reviewers' comments.

- Ashleigh Lin contributed in writing the paper and in the statistical analysis.

- Claudia M. Klier and Miriam R. Schäfer contributed in the recruitment and assessment of the sample.

- G. Paul Amminger developed the study design.

\section{Conflict of Interest}

None.

\section{Acknowledgements} None.

\section{References}

American Psychiatric Association, 1994. Diagnostic and Statistical Manual of Mental Disorders, Fourth ed. American Psychiatric Association, Washington, DC

Amminger, G.P., McGorry, P.D., 2012. Update on omega-3 polyunsaturated Fatty acids in early-stage psychotic disorders. Neuropsychopharmacology 37 (1), 309-310.

Amminger, G.P., Schäfer, M.R., Papageorgiou, K., Klier, C., Cotton, S.M., Harrigan, S.M., Mackinon, A., Mackinnon, A., McGorry, P.D., 2010. Long-chain omega-3 fatty acids for indicated prevention of psychotic disorders. A randomized, placebocontrolled trial. Arch. Gen. Psychiatry 67 (2), 146-154.

Amodio, D.M., Frith, C.D., 2006. Meeting of minds: the medial frontal cortex and social cognition. Nat. Rev. Neurosci. 7, 268-277.

Antshel, K.M., Fremont, W., Roizen, N.J., Shprintzen, R., Higgins, A.M., Dhamoon, A., Kates, W.R., 2006. ADHD, major depressive disorder, and simple phobias are prevalent psychiatric conditions in youth with velo-cardio-facial syndrome. J. Am. Acad. Child Adolesc. 45, 596-603.

Antshel, M., Fremont, M., Kates, W.R., 2008. The neurocognitive phenotype in velo-cardiofacial syndrome: a developmental study prospective. Dev. Disabil. Res. 14, 43-51.

Antshel, K.M., Shprintzer, R., Fremont, W., Higgins, A.M., Faraone, S.V., Kates, W.R. 2010. Cognitive and psychiatric predictors to psychosis in velocardiofacial syndrome: a 3-year follow-up study. J. Am. Acad. Child Adolesc. Psychiatry 49, 333-344. 
Arinami, T., 2006. Analyses of the associations between the genes of 22q11 deletion syndrome and schizophrenia. J. Hum. Genet. 51, 1037-1045.

Bassett, A.S., Chow, E.W., 1999. 22q11 deletion syndrome: a genetic subtype of schizophrenia. Biol. Psychiatry 46, 882-891.

Bassett, A.S., Chow, E.W., Abdel Malik, P., Gheorghiu, M., Husted, J., Weksberg, R., 2003. The schizophrenia phenotype in 22q11 deletion syndrome. Am. J. Psychiatry 160, 1580-1586.

Birchwood, M., McGorry, P., Jackson, H., 1997. Early intervention in schizophrenia. Br. J. Psychiatry $170,2-5$.

Birchwood, M., Todd, P., Jackson, C., 1998. Early intervention in psychosis. The critical period hypothesis. Br. J. Psychiatry Suppl. 172 (33), 53-59.

Chemerinski, E., Reichenberg, A., Kirkpatrick, B., Bowie, C.R., Harvey, P.D., 2006. Three dimensions of clinical symptoms in elderly patients with schizophrenia: prediction of six-year cognitive and functional status. Schizophr. Res. 85, 12-19.

Chow, E.W.C., Mikulis, D.J., Zipursky, R.B., Scutt, L.E., Weksberg, R., Bassett, A.S., 1999. Qualitative MRI findings in adults with 22q11 deletion syndrome and schizophrenia. Biol. Psychiatry 46, 1436-1442.

Davidson, J., Turnbull, C.D., Strickland, R., Miller, R., Graves, K., 1986. The MontgomeryAsberg Depression Scale: reliability and validity. Acta Psychiatr. Scand. 73, 544-548

Debbané, M., Glaser, B., David, M.K., Feinstein, C., Eliez, S., 2006. Psychotic symptoms in children and adolescents with 22q11.2 deletion syndrome: neuropsychological and behavioral implications. Schizophr. Res. 84, 187-193.

Feinstein, C., Eliez, S., Blasey, C., Reiss, A.L., 2002. Psychiatric disorders and behavioral problems in children with velocardiofacial syndrome: usefulness as phenotypic indicators of schizophrenia risk. Biol. Psychiatry 51, 312-318.

First, M.B., Spitzer, R.L., Gibbon, M., Williams, J.B.W., 2002. Structured Clinical Interview for DSM-IV-TR Axis I Disorders, Research Version, Patient Edition. (SCID I/P). Biometrics Research, New York State Psychiatric Institute, New York.

Fusar-Poli, P., Bonoldi, I., Yung, A.R., Borgwardt, S.J., Kempton, M., Valmaggia, L., et al. 2012. Predicting psychosis: meta-analysis of evidence of transition outcomes in individuals at high clinical risk. Arch. Gen. Psychiatry 69, 220-229.

Goghari, V.M., Sponheim, S.R., MacDonald, A.W., 2010. The functional neuroanatomy of symptom dimensions in schizophrenia: a qualitative and quantitative review of a persistent question. Neurosci. Biobehav. Rev. 34 (3), 468-486.

Gothelf, D., Presburger, G., Zohar, A.H., Burg, M., Nahmani, A., Frydman, M., 2004. Obsessive-compulsive disorder in patients with velocardiofacial (22q11 deletion) syndrome. Am. J. Med. Genet. B Neuropsychiatr. Genet. 126, 99-105.

Gothelf, D., Eliez, S., Thompson, T., Hinard, C., Penniman, L., Feinstein, C., Kwon, H., Jin, S., Jo, B., Antonarakis, S.E., Morris, M.A., Reiss, A.L., 2005. COMT genotype predicts longitudinal cognitive decline and psychosis in 22q11.2 deletion syndrome. Nat. Neurosci. 8, 1500-1502.

Gothelf, D., Penniman, L.C., Gu, E., Eliez, S., Reiss, A.L., 2007. Developmental trajectories of brain structure in adolescents with 22q11.2 deletion syndrome: a longitudinal study. Schizophr. Res. 96, 72-81.

Green, T., Gothelf, D., Glaser, B., Debbane, M., Frisch, A., Kotler, M., Weizman, A., Ellez, S., 2009. Psychiatric disorders and intellectual functioning throughout development in velocardiofacial (22q11.2 deletion) syndrome. J. Am. Acad. Child Adolesc. Psychiatry 48, 1060-1068.

Herbener, E.S., Harrow, M., Hill, S.K., 2005. Change in the relationship between anhedonia and functional deficits over a 20 -year period in individuals with schizophrenia. Schizophr. Res. 75, 97-105.

Insel, T.R., 2010. Rethinking schizophrenia. Nature 468, 187-193.

Karayiorgou, M., Morris, M.A., Morrow, B., Shprintzen, R.J., Goldberg, R., Borrow, J., Gos, A., Nestadt, G., Wolyniec, P.S., Lasseter, V.K., 1995. Schizophrenia susceptibility associated with interstitial deletions of chromosome 22q11. Proc. Natl. Acad. Sci. U. S. A. 92, 7612-7616.

Karayiorgou, M., Simon, T.J., Gogos, J.A., 2010. 22q11.2 microdeletions: linking DNA structural variation to brain dysfunction and schizophrenia. Nat. Rev. Neurosci. $11,402-416$.

Kaufman, J., Birmaher, B., Brent, D., Rao, U., 1997. Schedule for Affective Disorders and Schizophrenia for School-Age Children-Present Lifetime version (K-SADS-PL): initial reliability and validity data. J. Am. Acad. Child Adolesc. Psychiatry 36, 980-988.

Kay, S.R., Fiszbein, A., Opler, L.A., 1987. The positive and negative syndrome scale (PANSS) for schizophrenia. Schizophr. Bull. 13 (2), 261-276.

Klosterkötter, J., Hellmich, M., Steinmeyer, E.M., Schultze-Lutter, F., 2001. Diagnosing schizophrenia in the initial prodromal phase. Arch. Gen. Psychiatry 58, 158-164.

Lin, A., Wood, S.J., Nelson, B., Brewer, W.J., Spiliotacopoulos, D., Bruxner, A., Broussard, C., Pantelis, C., Yung, A.R., 2011. Neurocognitive predictors of functional outcome two to 13 years after identification as ultra-high risk for psychosis. Schizophr. Res. 132 (1), 1-7.

Mervis, C.B., Robinson, B.R., 2000. Expressive vocabulary ability of toddlers with Williams syndrome or Down syndrome: a comparison. Dev. Neuropsychol. 17, 111-126.

Milev, P., Ho, B.C., Arndt, S., Andreasen, N.C., 2005. Predictive values of neurocognition and negative symptoms on functional out-come in schizophrenia: a longitudinal first-episode study with 7-year follow-up. Am. J. Psychiatry 162, 495-506.

Morrison, A.P., French, P., Walford, L., Lewis, S.W., Kilcommons, A., Green, J., Parker, S., Bentall, R.P., 2004. Cognitive therapy for the prevention of psychosis in people at ultra-high risk: randomised controlled trial. Br. J. Psychiatry 185, 291-297.
Murphy, K.C., 2005. Annotation: velo-cardio-facial syndrome. J. Child Psychol. Psychiatry 46 (6), 563-571.

Murphy, K.C., Jones, L.A., Owen, M.J., 1999. High rates of schizophrenia in adults with velo-cardio-facial syndrome. Arch. Gen. Psychiatry 56, 940-945.

Murphy, B.P., Chung, Y.C., Park, T.W., McGorry, P.D., 2006. Pharmacological treatment of primary negative symptoms in schizophrenia: a systematic review. Schizophr. Res. 88, 5-25.

Myin-Germeys, I., van Os, J., 2007. Stress-reactivity in psychosis: evidence for an affective pathway to psychosis. Clin. Psychol. Rev. 27 (4), 409-424.

Oswald, W.D., Roth, E., 1987. Number Combination Test (Zahlen-Verbindungs-Test; ZVT). Testzentrale, Göttingen, Germany.

Parnas, J., 2000. The self and intentionality in the pre-psychotic stages of schizophrenia: phenomenological study. In: Zahavi, D. (Ed.), Exploring the self: Philosophical and psychopathological perspectives on self-experience. John Benjamins, Amsterdam, pp. $115-148$.

Robin, N.H., Shprintzen, R.J., 2005. Defining the clinical spectrum of deletion 22q11.2. Disabil. Rehabil. 147, 90-96.

Rockers, K., Ousley, O., Sutton, T., Schoenberg, E., Coleman, K., Walker, E., Cubells, J.F. 2009. Performance on the Modified Card Sorting Test and its relation to psychopathology in adolescents and young adults with 22q11.2 deletion syndrome. J. Intellect. Disabil. Res. 53 (7), 665-676.

Roid, G.M., Miller, L.J., 1997. Leiter International Performance Scale-Revised: Examiners Manual. Stoelting Co, Wood Dale, IL.

Ruhrmann, S., Frauke-Schultze-Lutter, F., Salokangas, R.K., Heinimaa, M., Linszen, D. Dingemans, P., Birchwood, M., Patterson, P., Juckel, G., Morrison, A., Lewis, S., von Reventlow, H.G., Klosterkotter, J., 2010. Prediction of psychosis in adolescents and young adults at high risk. Arch. Gen. Psychiatry 67, 241-251.

Scambler, P.J., Kelly, D., Lindsay, E., Williamson, R., Goldberg, R., Shprintznen, R. Wilson, D.I., Goodship, J.A., Cross, I.E., Burn, J., 1992. Velo-cardio-facial syndrome associated with chromosome 22 deletions encompassing the DiGeorge critical locus. Lancet 339, 1138-1139.

Schaer, M., Debbane, M., Bach, C.M., Ottet, M.C., Glaser, B., Thiran, J.P., Eliez, S., 2009 Deviant trajectories of cortical maturation in 22q11.2 deletion syndrome (22q11DS): a cross-sectional and longitudinal study. Schizophr. Res. 115, 182-190.

Schultze-Lutter, F., 2009. Subjective symptoms of schizophrenia in research and the clinic: the basic symptom concept. Schizophr. Bull. 35, 5-8.

Scutt, L., Chow, E.W.C., Weksberg, R., Honer, W.G., Bassett, A.S., 2001. Patterns of dysmorphic features in schizophrenia. Am. J. Med. Genet. 105, 713-723.

Shapiro, D.I., Cubells, J.F., Ousley, O.Y., Rockers, K., Walker, E.F., 2011. Prodromal symptoms in adolescents with 22q11.2 deletion syndrome and schizotypal personality disorder. Schizophr. Res. 129, 20-28.

Shprintzen, R.J., 2005. Velo-cardio-facial syndrome. Prog. Pediatr. Cardiol. 20, 187-193.

Sporn, A., Addington, A., Reiss, A.L., Dean, M., Gogtav, N., Potocnik, U., Greenstein, D. Hallmayer, J., Gochman, P., Lenane, M., Baker, N., Tossel, J., Rapoport, J.L., 2004 22q11 deletion syndrome in childhood onset schizophrenia: an update. Mol. Psychiatry 9, 225-226.

Stefansson, H., et al., 2008. Large recurrent microdeletions associated with schizophrenia. Nature $455,232-236$.

Stoddard, J., Niendam, T., Hendren, R., Carter, C., Simon, T.J., 2010. Attenuated positive symptoms of psychosis in adolescents with chromosome 22q11.2 deletion syndrome. Schizophr. Res. 118, 118-121.

Suzuki, M., Zhou, S.Y., Hagino, H., Niu, L., Takahashi, T., Kawasaki, Y., Matsui, M., Seto, H. Ono, T., Kurachi, M., 2005. Morphological brain changes associated with Schneider's first-rank symptoms in schizophrenia: a MRI study. Psychol. Med. 35, 549-560.

Swillen, A., Vogels, A., Devriendt, K., Fryns, J.P., 2000. Chromosome 22q11 deletion syndrome: update and review of the clinical features, cognitive-behavioral spectrum, and psychiatric complications. Am. J. Med. Genet. 97, 128-135.

Tek, C., Kirkpatrick, B., Buchanan, R.W., 2001. A five-year follow-up study of deficit and non-deficit schizophrenia. Schizophr. Res. 49, 253-260.

Vicari, S., Verucci, L., Carlesimo, G.A., 2007. Implicit memory is independent from IQ and age but not from etiology: evidence from Down and Williams syndrome. J. Intellect. Disabil. Res. 51, 932-941.

Xu, B., Roos, J.L., Levy, S., van Rensburg, E.J., Gogos, J.A., Karayorgou, M., 2008. Strong association of de novo copy number mutations with sporadic schizophrenia. Nat. Genet. 40, 880-885.

Yung, A.R., McGorry, P.D., McFarlane, C.A., Jackson, H.J., Patton, G.C., Rakkar, A., 1996 Monitoring and care of young people at incipient risk of psychosis. Schizophr. Bull. 22, 283-303.

Yung, A.R., Phillips, L.J., McGorry, P.D., McFarlane, C.A., Francey, S., Harrigan, S., Patton, G.C., Jackson, H.J., 1998. Prediction of psychosis. A step towards indicated prevention of schizophrenia Suppl. Br. J. Psychiatry 172 (33), 14-20.

Yung, A.R., Phillips, L.J., Yuen, H.P., Francey, S.M., McFarlane, C.A., Hallgren, M., McGorry, P.D., 2003. Psychosis prediction: 12-month follow-up of a high-risk ("prodromal") group. Schizophr. Res. 60 (1), 21-32.

Yung, A.R., Phillips, L.J., Yuen, H.P., McGorry, P.D., 2004. Risk factors for psychosis in an ultra high-risk group: psychopathology and clinical features. Schizophr. Res. 67, 131-142. 